\title{
The clinical challenge of achieving marginal adaptation in direct and indirect restorations
}

Karin Hermana Neppelenbroek

Co-Editor-in-Chief - Journal of Applied Oral Science

\section{Dear Readers,}

The clinical longevity of tooth-coloured restorations, whether direct or indirect, using composites and ceramics, greatly depends on the quality and stability of their marginal adaptation. In this issue, two interesting studies ${ }^{7,15}$ bring this subject and lead us to an exciting discussion.

Poor marginal adaptation of direct and indirect restorations exposes the dentin pulp complex to the oral environment, rendering the restorations susceptible to microleakage and plaque retention. This infiltration can lead to recurrent caries, postoperative sensitivity, pathologic pulpal changes, and restoration failures ${ }^{2}$.

Resin composites have been widely used in direct restorative procedures due to their good esthetics and ability to adhere to tooth structure using adhesive. Despite the development of the resin composites, the conversion of the resin composite monomers into a polymer network is accompanied by a bulk contraction leading to $1.67 \%-5.68 \%$ volumetric polymerization shrinkage ${ }^{5}$. When shrinkage stress exceeds the bond strength of the adhesive interface or the tooth's cohesive strength, the interfacial quality of the restoration is damaged, generating gap formation $(10-15 \mu \mathrm{m})^{9}$. Considered as most responsible for the poor adaptation of composite restorations, the polymerization shrinkage is an inherent characteristic of the composites and directly associated to their composition ${ }^{1,3}$.

To reduce the effects of polymerization shrinkage and the internal/ marginal gap formation, modifications in material composition have been suggested modifications in material composition (modified methacrylate organic matrixes ${ }^{7,17}$ and higher photoinitiator concentrations ${ }^{1}$, for example) as well in restoration techniques ${ }^{10}$. The latter includes C-factor control, incremental filling, modulation of the irradiance used for photocuring the composite, use of preheated composite resin, and applying flowable composite resin as a liner ${ }^{10,12,18}$.

In this context and considering the promising results $^{17}$ regarding the volumetric shrinkage in methacrylate organic matrixes modified with polyhedral oligomeric silsesquioxane (POSS), Correa Netto, et al. ${ }^{7}$ (2015) evaluated the marginal integrity of restorations produced with a model composite based on POSS. To produce the model composite,
25 wt. \% of UDMA from the methacrylate organic matrix was replaced by POSS (P25). Surprisingly, the authors observed that the methacrylate organic matrix modified by the addition of 25 wt. \% of POSS did not improve the marginal integrity of class I restorations. In addition, this model composite presented the highest volumetric polymerization shrinkage and polymerization shrinkage stress, thus reinforcing the need for future studies on the influence of other types of POSS molecules on the marginal adaptation and polymerization shrinkage.

The potential occurrence of adhesive or cohesive failures resulted from shrinkage stress is directly related to increasing cavity size and depth ${ }^{8}$. In large cavities, the use of indirect porcelain or resin composite restorations is a reliable alternative for reducing the adverse effects of bulk polymerization contraction of composites, resulting in lower risk of poor restoration adaptation as the volume of composite resin is strictly restricted to the cementing gap ${ }^{8}$. Apart from the problems previously mentioned for direct restorations, an insufficient adaptation of the indirect restorations also results in cement solubility, which may lead to more plaque accumulation, microleakage, secondary caries, and periodontal disease ${ }^{6}$.

The advent of computer-aided design/computeraided manufacturing ( $C A D / C A M)$ techniques revolutionized the indirect restorations over reduced material use and waste, digital data capture and computer-aided prosthesis design and manufacturing ${ }^{19}$. This process is recognized to reduce the risk of human error and the inaccuracy inherent in different restoration materials using controlled materials of industrial manufacturing, virtually free of imperfections and porosities. The larger the marginal gap, the earlier will be the rate of cement dissolution. While the ideal marginal gap range of cemented restorations should be 25-40 $\mu \mathrm{m}$, it is rarely reached clinically. For CAD/ CAM generated restorations, the approximate acceptable marginal gap discrepancies are less than $90 \mu \mathrm{m}^{11,16}$. The marginal and internal adaptation of CAD/CAM restorations is influenced by several factors such as fabrication stage, number of units in substructure, tooth location, tooth preparation design, material stiffness, type and thickness of the luting cement, type of CAM system, impression techniques, and CAD/CAM software versions/ parameter settings ${ }^{4,13-15}$. 
Based on the results of a recent study by $\mathrm{Ng}$, et al. ${ }^{14}$ (2014) that showed better marginal adaptation of complete crowns manufactured by intraoral scanning (digital impression) compared with crowns obtained by conventional techniques, Shim, et al. ${ }^{15}$ (2015) evaluated marginal and internal adaptation of restorations fabricated with different versions of the CAD/CAM software and the effect of different parameter settings. The authors concluded that compared to the CEREC version 3.8, the CEREC version 4.2 produced better fit of crown restorations, particularly in the axial wall and in the inner margin. The spacer parameter, specially set at $80 \mu \mathrm{m}$, was more accurately represented in the version 4.2 of the software than in the version 3.8. Conversely, the outer margin was not affected by the variables. Despite the promising results from the studies of $\mathrm{Ng}$, et al. ${ }^{14}$ (2014) and Shim, et al. ${ }^{15}$ (2015) there is paucity of information in the literature comparing the marginal gaps of CAD/CAM restorations made from conventional and digital impressions and with different versions of software and parameter settings.

The success of direct and indirect restorations depends on several factors; one of the most important is the marginal adaptation as demonstrated here by the studies of Correa Netto, et al. ${ }^{7}$ (2015) and Shim, et al. ${ }^{15}$ (2015). The major clinical challenge is the lack of longitudinal studies in vivo on new direct and indirect restorative materials and restorative techniques since they are in constant development and improvement. However, the clinician should know essentially how to indicate the correct restorative procedure, whether direct or indirect, always aiming at the preservation of tooth structure. In view of this statement, the clinician should continuously update scientifically to choose a direct or indirect material with properties aiming an accurate marginal adaptation to better predict the longevity of the restorations.

\section{References}

1- Alonso RC, Souza-Júnior EJ, Dressano D, Araújo GA, Rodriguez JM, Hipólito VD, Anauate-Netto C, et al. Effect of photoinitiator concentration on marginal and internal adaptation of experimental composite blends photocured by modulated methods. Eur J Dent. 2013;7(Suppl1):S1-8.

2- Amaral CM, Peris AR, Ambrosano GM, Pimenta LA. Microleakage and gap formation of resin composite restorations polymerized with different techniques. Am J Dent. 2004;17(3):156-60.

3- Atai M, Watts DC, Atai Z. Shrinkage strain-rates of dental resin-monomer and composite systems. Biomaterials 2005;26(24):5015-20.

4- Att W, Komine F, Gerds T, Strub JR. Marginal adaptation of three different zirconium dioxide three-unit fixed dental prostheses. J Prosthet Dent. 2009;101(4):239-47.

5- Bausch JR, de Lange K, Davidson CL, Peters A, de Gee AJ. Clinical significance of polymerization shrinkage of composite resins. J Prosthet Dent. 1982;48(1):59-67.
6- Block PL. Restorative margins and periodontal health: a new look at an old perspective. J Prosthet Dent. 1987;57:683-9.

7- Correa Netto LR, Guimarães HB, Almeida ERN, Poskus LT, Borges ALS, Silva EM. Marginal integrity of restorations produced with a model composite based on polyhedral oligomeric silsesquioxane (POSS). J Appl Oral Sci. 2015;23(5):450-8.

8- Dietschi D, Scampa U, Campanile G, Holz J. Marginal adaptation and seal of direct and indirect Class II composite resin restorations: an in vitro evaluation. Quintessence Int. 1995;26(2):127-38.

9- Dionysopoulos D, Koliniotou-Koumpia E. SEM Evaluation of internal adaptation of bases and liners under composite restorations. Dent J. 2014;2:52-64.

10- Dionysopoulos D, Papadopoulos C, Koliniotou-Koumpia E. The evaluation of various restoration techniques on internal adaptation of composites in class $v$ cavities. Int ] Biomater. 2014[cited 2015 Oct 03];2014:148057. Available from:<http:dx.doi.org/ $10.1155 / 2014 / 148057>$.

11- Euán R, Figueras-Álvarez O, Cabratosa-Termes J, Brufaude Barbera M, Gomes- Azevedo S. Comparison of the marginal adaptation of zirconium dioxide crowns in preparations with two different finish lines. J Prosthodont. 2012;21:291-5.

12- Feilzer AJ, De Gee AJ, Davidson CL. Setting stress in composite resin in relation to configuration of the restoration. J Dent Res. 1987;66:1636-9.

13- Gonzalo E, Suarez MJ, Serrano B, Lozano JF. Comparative Analysis of two measurement methods for marginal fit in metal-ceramic and zirconia posterior FPDs. Int J Prosthodont. 2009;22(4):374-7.

14- $\mathrm{Ng} \mathrm{J,} \mathrm{Ruse} \mathrm{D,} \mathrm{Wyatt} \mathrm{C.} \mathrm{A} \mathrm{comparison} \mathrm{of} \mathrm{the} \mathrm{marginal} \mathrm{fit} \mathrm{of}$ crowns fabricated with digital and conventional methods. J Prosthet Dent. 2014;112(3):555-60.

15- Shim JS, Lee JS, Lee JY, Choi YJ, Shin SW, Ryu JJ. Effect of software version and parameter settings on the marginal and internal adaptation of crown fabricated with the CAD/CAM system. J Appl Oral Sci. 2015;23(5):515-22.

16- Syrek A, Reich G, Ranftl D, Klein C, Cerny B, Brodesser J. Clinical evaluation of all-ceramic crowns fabricated from intraoral digital impressions based on the principle of active wavefront sampling. J Dent. 2010;38(7):553-9

17- Wu X, Sun Y, Xie W, Liu Y, Song X. Development of novel dental nanocomposites reinforced with polyhedral oligomeric silsesquioxane (POSS). Dent Mater. 2010;26:456-62.

18- Wydra JW, Cramer NB, Stansbury JW, Bowman CN. The reciprocity law concerning light dose relationships applied to BisGMA/TEGDMA photopolymers: theoretical analysis and experimental characterization. Dent Mater. 2014;30:605-12.

19- Zarauz C, Valverde A, Martinez-Rus F, Hassan B, Pradies G. Clinical evaluation comparing the fit of all-ceramic crowns obtained from silicone and digital intraoral impressions. Clin Oral Investig. In press 2015[cited 2015 Oct 03]. Available from: <http:dx.doi. org/10.1007/s00784-015-1590-5>. 